\title{
SOMMAIRE
}

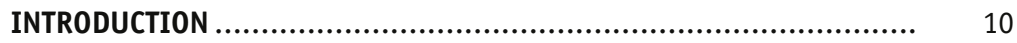

CALCULEZ VOS POINTS ! ......................................................... 13

\section{QUIZ 1}

Quiz 1, Manche 1 : La Terre et les Lunes...................................... 17

Q1. Compter les Lunes ............................................................ 19

Q2. Le blues de la station spatiale ................................................ 21

Q3. Une question de chute.......................................................... 23

Q4. Le trou noir de la Terre...................................................... 25

Q5. L'homme qui tomba à travers la Terre..................................... 27

Q6. Monnaie lunaire ............................................................... 29

Q7. La mesure du monde ............................................................ 31

Q8. Des œufs dans l'espace ......................................................

Quiz 1, Manche 2 : Divers ........................................................

Q1. La science des spaghettis................................................... 37

Q2. Gagner la médaille d'or de physique....................................... 39

Q3. La question Carrington....................................................... 41

Q4. Une température absolue ................................................... 43 
Q5. La menace des friandises au cinéma ....................................... 45

Q6. Une -ologie distinguée ..................................................... 47

Q7. Un éléphant extraordinaire ................................................... 49

Q8. L'heure du père Noël.......................................................... 51

Quiz 1, Manche 3 : Mathématiques ..............................................

Q1. Choisissez une réponse, n'importe laquelle............................... 55

Q2. Cauchemar de joueur de foot ...............................................

Q3. Une question moyenne ....................................................... 59

Q4. Un pourcentage aléatoire ..................................................... 61

Q5. Le symbole de célébrité de Robert Recorde ................................ 63

Q6. Diagonale irrationnelle.......................................................... 65

Q7. La science des sept lieues ...................................................... 67

Q8. Il suffit de suivre la côte........................................................ 69

Quiz 1, Manche 4 : Biologie ........................................................ 71

Q1. Sœur Anne, ne vois-tu rien venir ? ........................................ 73

Q2. En cellule........................................................................

Q3. Couleur rouge sang............................................................ 77

Q4. Oiseau d'altitude ...............................................................

Q5. Tirée par les cheveux............................................................. 81

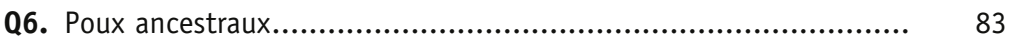

Q7. Une question bleue ........................................................... 85

Q8. Araignée légendaire.......................................................... 87

Quiz 1, Manche 5 : Technologie ................................................... 89

Q1. La première voix de son maitre .............................................. 91

Q2. Ordinateur consciencieux .................................................... 93

Q3. Un moment éclairant .......................................................... 95

Q4. Le blues de Big Blue............................................................ 97

Q5. Entreprise atomique .......................................................... 99

Q6. Débordant d'idée.............................................................. 101

Q7. La folie des brevets ........................................................... 103

Q8. Mécanismes de Matrix ....................................................... 105 
Quiz 1, Manche 6 : Chimie .......................................................... 107

Q1. Jeux d'esprit moléculaire.................................................... 109

Q2. Ce n'est qu'un gaz ............................................................. 111

Q3. Liaisons dangereusement chaudes ......................................... 113

Q4. Faire passer la pilule........................................................... 115

Q5. Que d'eau! Que d'eau !........................................................ 117

Q6. Avalez la pilule................................................................ 119

Q7. Il y a le sel, le soleil et la mer.............................................. 121

Q8. Combien de E dans bleuet ?.................................................. 123

Quiz 1, Première manche spéciale : Scientifiques célèbres ................... 125

Quiz 1, Deuxième manche spéciale : Science cryptique ....................... 129

QUIZ 2

Quiz 2, Manche 1 : Physique ..................................................... 133

Q1. Les pommes d'Isaac........................................................ 135

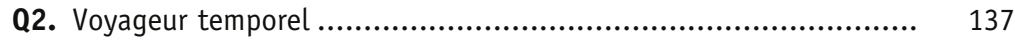

Q3. Quelque part sur l'arc-en-ciel .................................................. 139

Q4. Le professeur électronique.................................................... 141

Q5. Un boulot pour Scotty ....................................................... 143

Q6. Un ballet de balles ............................................................ 145

Q7. Le pouvoir de l'absurde .......................................................... 147

Q8. L'astuce de Gamow ............................................................. 149

Quiz 2, Manche 2 : Biologie ...................................................... 151

Q1. Question de goût ............................................................. 153

Q2. Nos cousines les souris ...................................................... 155

Q3. Le lion qui changeait de couleur ............................................ 157

Q4. Qui prend tout son sens................................................... 159

Q5. Le demi-dinosaure............................................................ 161

Q6. L'autre question de goût ....................................................... 163 
Q7. À propos de Dolly.................................................................. 165

Q8. L'ombre sur les souris ........................................................ 167

Quiz 2, Manche 3 : Divers ....................................................... 169

Q1. Un train et deux pigeons ................................................... 171

Q2. Lumière fantastique.......................................................... 173

Q3. Énigme alphanumérique .................................................... 175

Q4. Le thé de vache ............................................................... 177

Q5. La merveille de Wardenclyffe ................................................. 179

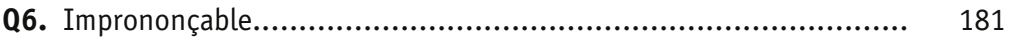

Q7. Hydratation hasardeuse...................................................... 183

Q8. Un sauna naturel ............................................................... 185

Quiz 2, Manche 4 : Histoire........................................................ 187

Q1. Naissance de Bacon ........................................................... 189

Q2. L'Alma mater d'Albert.......................................................... 191

Q3. Sur un nuage neuf............................................................. 193

Q4. Passage de relais ........................................................... 195

Q5. Soucoupes secrètes............................................................. 197

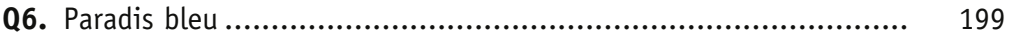

Q7. Fusil à rayon antique .......................................................... 201

Q8. Trouvez le point commun .................................................... 203

Quiz 2, Manche 5 : Espace....................................................... 205

Q1. Lumière voyageuse ........................................................... 207

Q2. Un ballet d'étoiles......................................................... 209

Q3. Connaissance universelle ...................................................... 211

Q4. Rendez-vous du Soleil et de la Lune ...................................... 213

Q5. Le poids du système solaire .................................................. 215

Q6. Voyageurs à Très Grande Vitesse ............................................ 217

Q7. Valeurs vénusiennes ......................................................... 219

Q8. Une singularité singulière ................................................. 221 
Quiz 2, Manche 6 : Technologie .................................................. 223

Q1. Arme à recharger ............................................................... 225

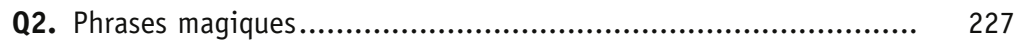

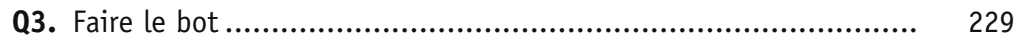

Q4. Alerte optique à Malibu....................................................... 231

Q5. Composition numérique......................................................... 233

Q6. Focus sur les lentilles ....................................................... 235

Q7. Rêves numériques............................................................ 237

Q8. Cuisine au klystron ........................................................ 239

Quiz 2, Première manche spéciale : Table périodique......................... 241

Quiz 2, Deuxième manche spéciale : NASA ..................................... 245 
